\title{
CORRESPONDENCE
}

\section{Archiving lessons from radiobiology}

Rescuing endangered primary data is important (Nature 468, 17; 2010). Even more crucial is to archive it at the time it is generated. This lesson has been learned by the radiobiology community, who took on that challenge 25 years ago.

The past 60 years have seen many large-scale studies of radiation effects on animals. The scale, cost (estimated at US $\$ 2$ billion today) and ethical aspects of these experiments make them unlikely to be repeated. However, the data could usefully be reanalysed in the light of new paradigms in radiobiology.

These endangered data were deposited between 1985 and 1999 in the International Radiobiology Archives (IRA): they include results collected during 1960-98 on more than 460,000 animals in Europe, the United States and Japan. The IRA is now integrated into a legacy database, the European Radiobiology Archive (ERA), a project funded by the European Commission (see go.nature.com/ evbdFv).

Development of the ERA taught us that integrating legacy data into a standard format is difficult. But the data must be searchable and usable to prevent the database becoming an information graveyard.

Sustainability is also a problem. It is hard to find agencies and institutions that are prepared to fund long-term archives. Fortunately, Germany's Federal Office for Radiation Protection has committed to maintaining the ERA database - an important asset for the radiobiology community.

The European Commission's STORE project will act as a data warehouse and radiobiological resource directory. Its importance is recognized by the Multidisciplinary European Low-Dose Initiative (www. melodi-online.eu), which coordinates policy on low-dose radiation research.

Paul N. Schofield University of Cambridge, UK.

ps@mole.bio.cam.ac.uk

Soile Tapio Helmholtz Zentrum München, Institute of Radiation Biology (ISB), Germany.

Bernd Grosche Federal Office for Radiation Protection, Germany.

\section{The politics of climate (dis)belief}

The most telling feature of the climate-sceptic movement (aside from the large amount of money behind it) is that it is organized along the left-right political axis, with the left generally being sympathetic to climate science and the right far less so.

Liberals usually view science as a force for change that could benefit society. For conservatives, science typically serves to reinforce the status quo by making society more efficient and more powerful. This is not to brand the right as anti-science (see Nature 468, 508; 2010): as an objective truth, science is an appealing bulwark against the relativism of liberals.

Scepticism about global warming illustrates the right's difficulty in conceptualizing the group (rather than the individual) as a political actor. Conservatives traditionally believe that the course of history is decided by a few heroic figures - Churchill, Napoleon, and so on. The left tends to sideline such figures in favour of the mass movements they spearheaded. The right's popular argument that global warming is a hoax neatly demonstrates this. After all, a hoax demands a hoaxer, a 'heroic villain' who is faking data and distributing bribes behind the scenes.

If one believes in mass movements, it is easy to imagine a mass movement of waste - a kind of rotten plebiscite cast against our planet. If one does not, global warming cannot help but seem unlikely, no matter how strong the evidence.

Francis Nicholson Coventry, UK. francisnicholson@gmail.com

\section{How to conserve the tropics as they warm}

To make tropical forests more resilient to climate change, we need a coordinated effort to refocus conservation tools at regional and international levels.

The tools include expansion of protected areas, control of fires, and application of REDD policy ('reduced emissions from deforestation and forest degradation'). The latter is intended to protect forest carbon but lacks explicit mechanisms for increasing forest resilience.

These conservation instruments should be focused on two goals. First, they should be deployed to increase the large-scale connectivity of tropical forests, especially across latitudinal and elevational gradients, to facilitate range shifts by tropical species in response to future climate change. Second, they should be coordinated to reduce or halt agricultural expansion in areas of rapid deforestation, especially when such areas are also susceptible to drying, as in the Amazon's arc of deforestation.

The biodiversity benefits of REDD projects and new protected areas would be augmented by strategically locating them to protect connectivity between major ecozones - for example, between the Amazon lowlands and the uplands of the Brazilian and Guiana shields - or to span large-scale moisture gradients, as in the Central Amazonian Conservation Corridor.
In tropical Asia, the strategic use of REDD projects could help to link existing protected areas into large-scale conservation networks in central Borneo, in the forests along the border of Thailand and Myanmar and in the Annamite Mountains of Laos and Vietnam.

Similarly, a more strategic approach is needed for fire-control education and regulation. Although they will always be important in southeast Asia, we can predict when these measures will be crucial: after El Niño events, for example, which can dry out Indonesia's and Malaysia's tropical forests and increase the risk of huge fires.

Jedediah Brodie University of Montana, USA. jedediah.brodie@gmail.com Eric Post Pennsylvania State University, USA.

William Laurance James Cook University, Australia.

\section{Faraday on the fiscal benefits of science}

In considering Daniel Sarewitz's view of the value of scientific research in today's difficult economic times (Nature 468, $135 ; 2010)$, it is worth recalling physicist Michael Faraday's reply in the 1850 s to William Gladstone, then British chancellor of the exchequer. Questioned about the practical value of electricity, Faraday answered: "One day, sir, you may tax it." Michael Polymenis Texas A\&M University, USA. polymenis@tamu.edu

CONTRIBUTIONS Items for Correspondence may be submitted to correspondence@nature. com after consulting the author guidelines at http:// go.nature.com/cMCHno. 